\title{
Research on Acoustic Emission and Electromagnetic Emission Characteristics of Rock Fragmentation at Different Loading Rates
}

\author{
Fujun Zhao ${ }^{D}$, Yu Li, Zhouyuan Ye, Yong Fan, Siping Zhang, \\ Haifan Wang, and Yonghong Liu \\ School of Resource Environment and Safety Engineering, Hunan University of Science and Technology, Xiangtan 411201, China \\ Correspondence should be addressed to Fujun Zhao; zfjxxn@263.net
}

Received 26 October 2017; Accepted 28 March 2018; Published 3 May 2018

Academic Editor: Caiping Lu

Copyright (C) 2018 Fujun Zhao et al. This is an open access article distributed under the Creative Commons Attribution License, which permits unrestricted use, distribution, and reproduction in any medium, provided the original work is properly cited.

\begin{abstract}
The relationships among the generation of acoustic emission, electromagnetic emission, and the fracture stress of rock grain are investigated, which are based on the mechanism of acoustic emission and electromagnetic emission produced in the process of indenting rock. Based on the relationships, the influence of loading rate on the characteristics of acoustic emission and electromagnetic emission of rock fragmentation is further discussed. Experiment on rock braking was carried out with three loading rates of $0.001 \mathrm{~mm} / \mathrm{s}, 0.01 \mathrm{~mm} / \mathrm{s}$, and $0.1 \mathrm{~mm} / \mathrm{s}$. The results show that the phenomenon of acoustic emission and electromagnetic emission is produced during the process of loading and breaking rock. The wave forms of the two signals and the curve of the cutter indenting load show jumping characteristics. Both curves have good agreement with each other. With the increase of loading rate, the acoustic emission and electromagnetic emission signals are enhanced. Through analysis, it is found that the peak count rate, the energy rate of acoustic emission, the peak intensity, the number of pulses of the electromagnetic emission, and the loading rate have a positive correlation with each other. The experimental results agree with the theoretical analysis. The proposed studies can lead to an in-depth understanding of the rock fragmentation mechanism and help to prevent rock dynamic disasters.
\end{abstract}

\section{Introduction}

Machinery is frequently used to break rock in mining, tunnel driving, drilling blasting and oil-gas drilling, and other geotechnical engineering fields. The intrusive rock fragmentation mechanism is of great importance, since the intrusive rock is the basic form of mechanical broken rock. Rock fragmentation mainly related to the rock crack initiation and propagation in the process of indenting rock. The process of crack propagation can be described as the stress relaxation process and releasing parts of the internal energy in the rock. As a result, this part of the energy is manifested in the form of elastic waves and electromagnetic waves, generating acoustic emission (AE) and electromagnetic emission (EME) $[1,2]$. The $\mathrm{AE}$ and EME signals can reflect the crack propagation and energy evolution of rock material continuously and in real-time [3-7]. Nowadays, most of researchers concentrated on the studies of the $\mathrm{AE}$ and EME generation, propagation, and characteristics during the rock break process [8-22]. Dong et al. $[23,24]$ studied the article on theoretical and experimental studies of localization methodology for $\mathrm{AE}$ and microseismic sources without premeasured wave velocity in mines. However, our works focus on the study of the rock fracture damage mechanism under different loading rates with the help of AE and EME signal. Therefore, in this paper, the brittle rock granite, which is common in engineering as research project, is used to study the mechanism of the $\mathrm{AE}$ and EME at different loading rates. Our work can lead to an in-depth understanding of the rock fragmentation mechanism and help to prevent rock dynamic disasters.

\section{Theoretical Analysis}

2.1. Effect of Loading Rate on AE. AE is generated by rapidly releasing energy in the local domain source of rock material generating the transient elastic wave, and the characteristic 
parameters of $\mathrm{AE}$ are parameters that represent the whole or individual behavior properties of the rock particles in the whole process. According to the principle of AE testing, the total relationship of $\mathrm{AE}$ is as follows [25]:

$$
N=\frac{f}{\beta} \int \ln \left(\sqrt{\frac{E_{g}}{E_{g 0}}}\right) d \phi,
$$

where $N$ is the total number of $\mathrm{AE}, f$ is working frequency, $\beta$ is the attenuation coefficient of AE wave, $E_{g}$ is the AE energy released by rock particle failure, $E_{g 0}$ is the initial loading $\mathrm{AE}$ energy, and $\phi$ is the number of $\mathrm{AE}$ events for particle deformation and failure.

The experimental results show [26] that, in the wide frequency band $(0.1 \sim 1.0 \mathrm{MHz})$, the working frequency $f$ and the attenuation coefficient beta $\beta$ are proportional functions, so the upper formula can be simplified as

$$
N=A \int \ln \left(\sqrt{\frac{E_{g}}{E_{g 0}}}\right) d \phi
$$

where $A$ is constant, $A=f / \beta$.

In a micropoint of view, when the rock is broken by a single grain under external stress, the magnitude for the released AE energy is

$$
E_{g}=\frac{\sigma^{2}}{2 E} d^{3}
$$

where $\sigma$ is external stress, $E$ is elastic modulus, and $d$ is grain size.

If the stress threshold is seen as the stress at which the grain begins to break, the energy emitted by the initial acoustic emission is (stress is $\sigma_{0}$ )

$$
E_{g 0}=\frac{\sigma_{0}^{2}}{2 E} d^{3}
$$

Since the total probability of rock grain fragmentation obeys the Weibull distribution [1], a grain fragmentation produces an $\mathrm{AE}$ event. The total number of $\mathrm{AE}$ events produced by the rupture of rock grain under external stress (stress is $\sigma$ ) is

$$
\phi=(L+1)\left\{1-\exp \left[-B\left(\frac{\sigma}{\sigma_{0}}\right)^{m}\right]\right\} .
$$

Take the general circumstances into account $(\phi \ll L)$, so the type can be simplified as

$$
\phi=L B\left(\frac{\sigma}{\sigma_{0}}\right)^{m}
$$

where $L$ is the number of existing grains of rocks, $B$ is a constant related to rock properties, and $m$ is a constant associated with rock fracture.

Substituting (3), (4), and (6) into (2), the total number of $\mathrm{AE}$ is

$$
N=A L B m\left[\left(\frac{\sigma}{\sigma_{0}}\right)^{m}\left(\frac{\ln \sigma-\ln \sigma_{0}}{m}-\frac{1}{m^{2}}\right)+\frac{1}{m^{2}}\right] .
$$

The relationship between $\mathrm{AE}$ rate and stress and loading rate is obtained by taking the derivative of (7):

$$
\frac{d N}{d t}=\frac{A L B m}{\sigma_{0}}\left(\frac{\sigma}{\sigma_{0}}\right)^{m-1} \ln \left(\frac{\sigma}{\sigma_{0}}\right) \frac{d \sigma}{d t} .
$$

As a result, the relationship between the $\mathrm{AE}$ rate of the cutter is derived. According to (8), the AE rate is related to the loading rate, and the $\mathrm{AE}$ rate increases with the increase of loading rate.

2.2. Effect of Loading Rate on EME. Many scholars have analyzed the mechanism of EME from different standpoints. When the rock is loading, the rock crack acceleration generates charge and the charges' motion produces EME. Based on the piezoelectric effect of crystal, Chen et al. [27] proposed that the phenomenon of EME during the rock broken is caused by the destruction of the piezoelectric crystal, which leads to the instantaneous charge movement.

Let the voltage of the crystal element be $d l \times d l \times d l$, the piezoelectric modulus be $p$, and the microelement be destroyed during compressive stress $\sigma$; then, the charge of the microelement end surface is

$$
q=p \sigma(d l)^{2},
$$

where $q$ is the charge amount.

The electric field intensity of EME can be obtained by the EME model [28]:

$$
E=\left|\frac{q a \sin ^{2} \theta}{4 \pi \varepsilon_{0} c^{2} r}\right|
$$

where $a$ is the acceleration of crack propagation, $q$ is the charge amount, $c$ is the speed of light, $r$ is the charge distance, and $\varepsilon_{0}$ is the vacuum dielectric constant.

According to the mechanical model of the broken rock to analyze the force of the tool rock fragmentation [29], the tool intrudes into the broken rock and overcomes the rock breaking strength and frictional force and generates the tooling force of the rock:

$$
P=R+F_{m}=2 h l \sigma_{c}\left(\tan \frac{\alpha}{2}+f\right),
$$

where $h$ is invasion depth, $\alpha$ is the tool edge angle, $l$ is tool length, $\sigma_{c}$ is the rock uniaxial compressive strength, and $f$ is the friction coefficient.

Due to the relationship between loading rate and rock single axial compressive strength [30],

$$
\log \sigma_{c}=\frac{1}{n+1} \log v+A
$$

where $n$ is the coefficient of rock corrosion, $n \geq 0 ; v$ is the loading rate; and $A$ is the dimensionless coefficient.

Substitute formula (12) into formula (11). The relationship between the intrusion force and loading rates is obtained:

$$
P=2 l K\left(\tan \frac{\alpha}{2}+f\right) \cdot h \cdot v^{b}
$$

among them $K=10^{A}, b=1 /(n+1), 0<b \leq 1$. 


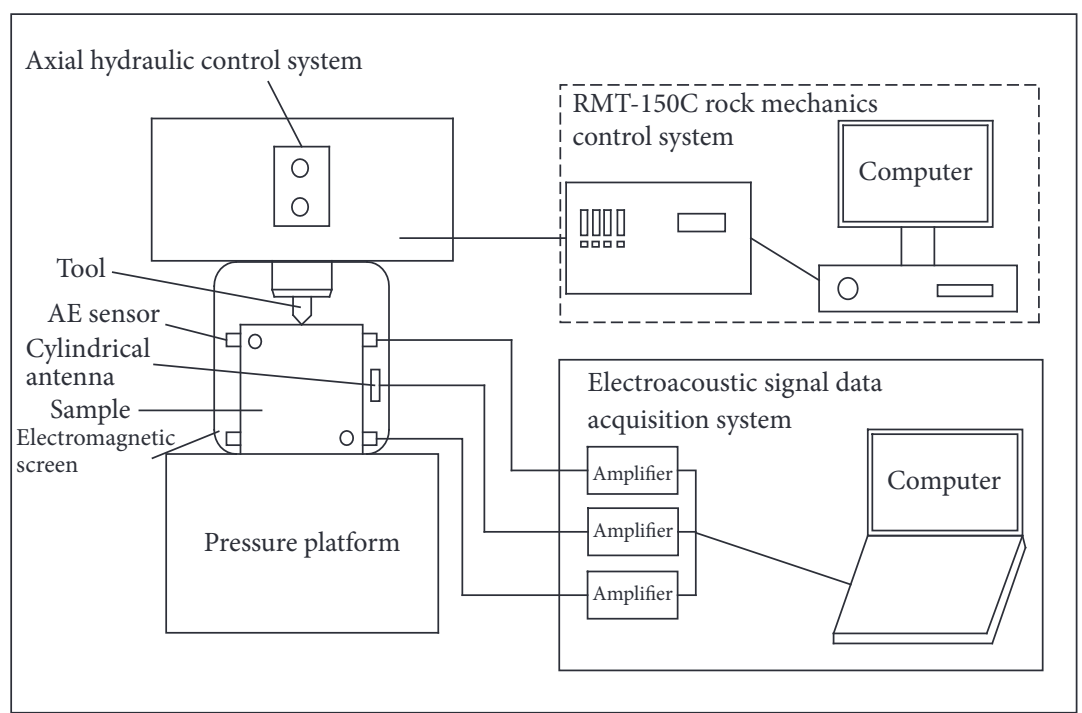

(a) Sketch map of experimental device

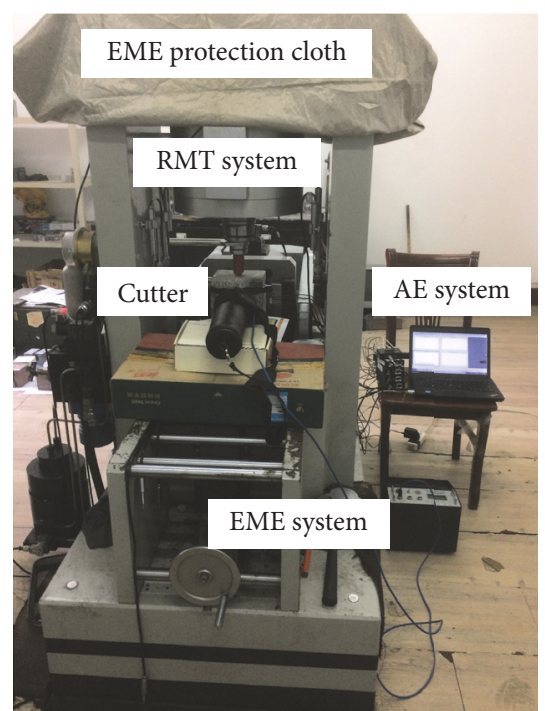

(b) Physical map of experimental device

FIGURE 1: Diagram of test equipment.

The piezoelectric microelement is assumed to be the unit piezoelectric microelement. By substituting formula (13) into (10), the electromagnetic emission intensity of the broken rock was derived.

$$
E=\left|\frac{\operatorname{palK}(\tan (\alpha / 2)+f) h v^{b} \sin ^{2} \theta}{2 \pi \varepsilon_{0} c^{2} r}\right|
$$

Through the above analysis, the relationship between the EME strength of the cutter is derived. According to formula (14), the EME intensity is related to the loading rate, and the intensity of EME increases with the increase of loading rate.

\section{Testing System}

The experimental system consists of loading system and AE and EME collection system, shown in Figure 1. The loading system of the test is the RMT-150C pressure testing machine; the signal acquisition system consists of AEwin-USB AE detection system, KBD5 EME monitoring system, and EME shielding system. To eliminate the friction between cutter and specimen face and environmental noise of the AE and EME signals, the total system gain is set to $76 \mathrm{~dB}$ (which is placed in front of $40 \mathrm{~dB}$, the main discharge is $36 \mathrm{~dB}$ ), the threshold value is set to $40 \mathrm{~dB}$, and the sampling frequency is set to $5 \mathrm{Msps}$. The sample size of granite specimen is $150 \mathrm{~mm} \times$ $150 \mathrm{~mm} \times 150 \mathrm{~mm}$; the physical and mechanical parameters are as follows: modulus of elasticity $E=21.35 \mathrm{GPa}$, density $\boldsymbol{\rho}=2.6 \times 10^{3} \mathrm{~kg} / \mathrm{m}^{3}$, compressive strength $\boldsymbol{\sigma}_{c}=106.46 \mathrm{MPa}$, and tensile strength $\sigma_{t}=7.65 \mathrm{MPa}$. The displacement control method was adopted to perform a type-tool static intrusion breaking experiment, and the loading rate was set at three levels: $0.001 \mathrm{~mm} / \mathrm{s}, 0.01 \mathrm{~mm} / \mathrm{s}$, and $0.1 \mathrm{~mm} / \mathrm{s}$.
TABLE 1: Characteristics of AE and EME.

\begin{tabular}{lccc}
\hline \multirow{2}{*}{ Comparison parameter } & \multicolumn{3}{c}{ Loading rate $\left(\mathrm{mm} \cdot \mathrm{s}^{-1}\right)$} \\
& 0.001 & 0.01 & 0.1 \\
\hline Limit load $(\mathrm{kN})$ & 144.86 & 169.02 & 175.32 \\
Peak AE rate $\left(\cdot \mathrm{s}^{-1}\right)$ & & & \\
$\quad$ Count rate & 30303 & 36329 & 38360 \\
$\quad$ Energy rate & 30876 & 120356 & 189748 \\
$\quad$ Load level $(\%)$ & 96 & 96 & 95 \\
Peak EME & & & \\
Strength (mv) & 133 & 153 & 261 \\
Pulse number & 18509 & 35000 & 48000 \\
Load level $(\%)$ & 95 & 97 & 96 \\
\hline
\end{tabular}

\section{Testing Results}

4.1. AE and EME Characteristics at Different Loading Rates. Experiments are conducted where a single cutter is penetrated into granite under different loading rates. The AE signal parameters, the EME signal parameters, and the load are recorded as shown in Table 1 and Figures 2 and 3, respectively. Through the analysis of the influence of the loading rate on the $\mathrm{AE}, \mathrm{EME}$, and rock breaking characteristics, it can be concluded as follows.

(1) As shown in Figures 2 and 3, AE and EME signal are basically increased with the increase of load. When loading rate is $0.001 \mathrm{~mm} / \mathrm{s}$, the jump phenomenon happens when the cutter is penetrated into the rock $(\mathrm{A}, \mathrm{B}, \mathrm{C}, \mathrm{D})$; $\mathrm{AE}$ and $\mathrm{EME}$ signals also have a sudden increase. AE and EME have same tendency under different loading rate.

(2) The loading rate affects the damage of rock. The greater the loading rate, the greater the rock fragmentation. 

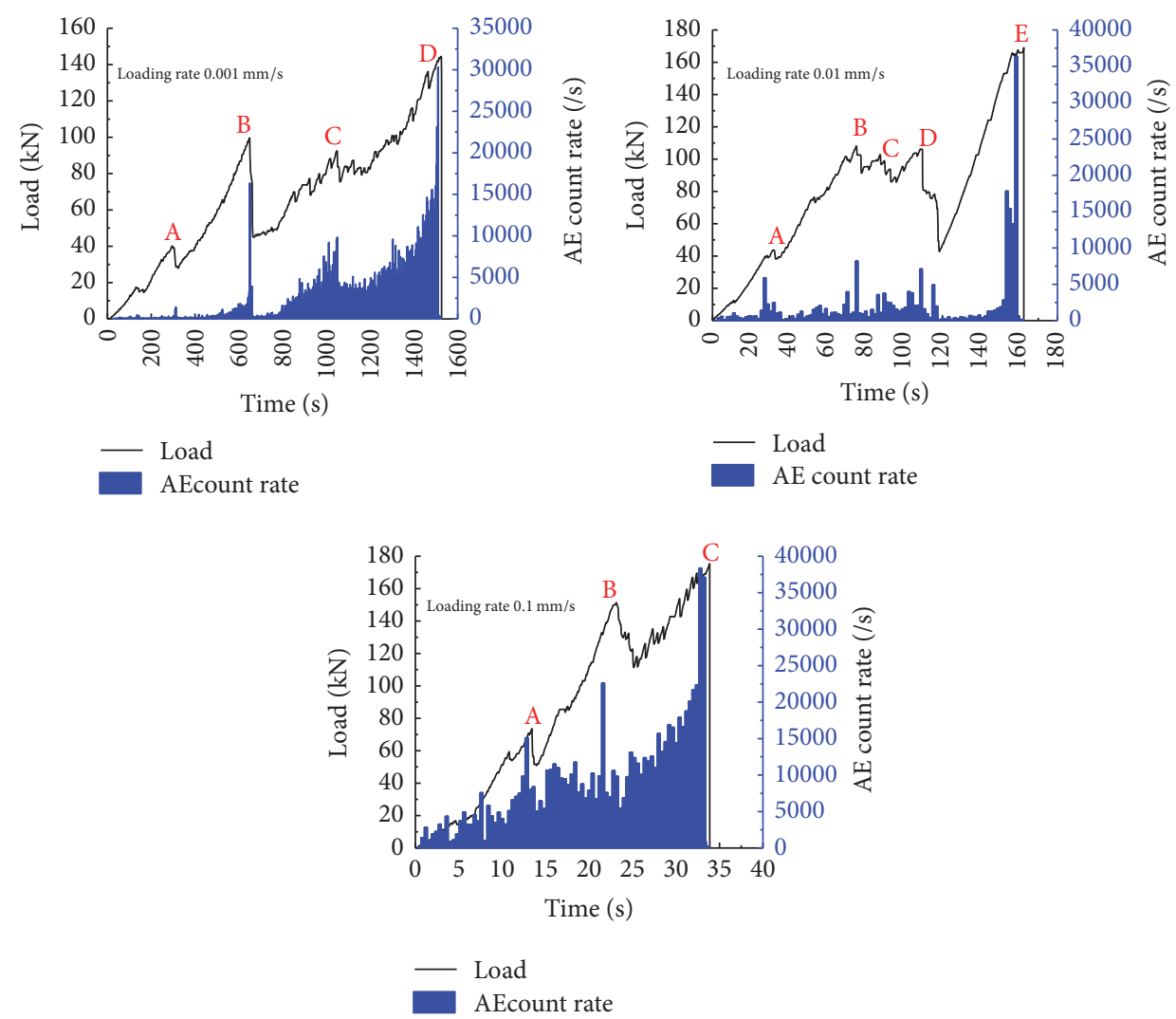

(a)

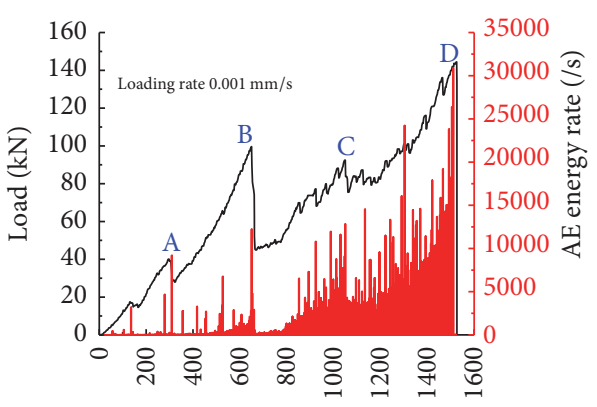

Time (s)

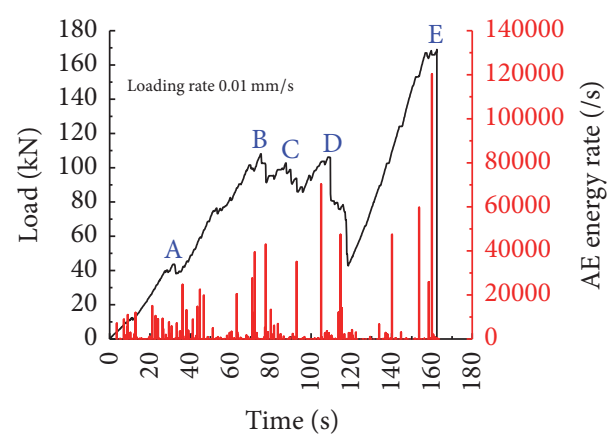

Load
AE energy rate

- Load

AE energy rate

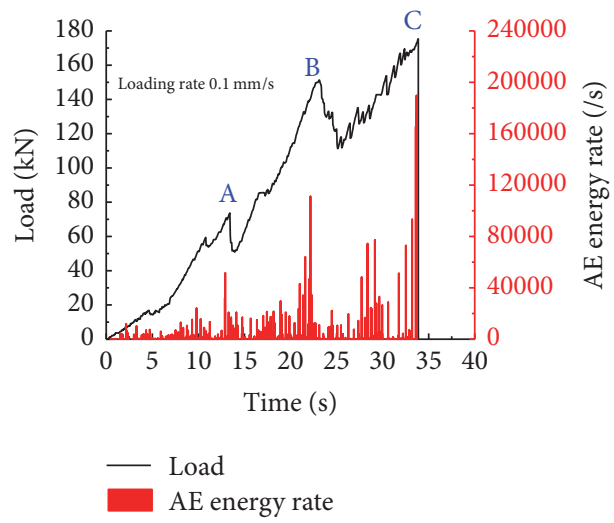

(b)

FIgURE 2: Curves of AE parameters under different loading rates. 


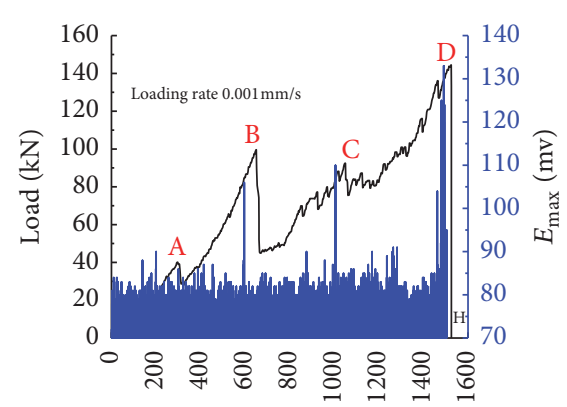

Time (s)

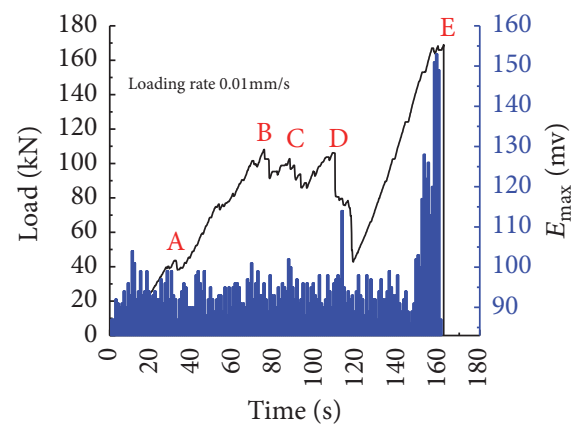

- Load

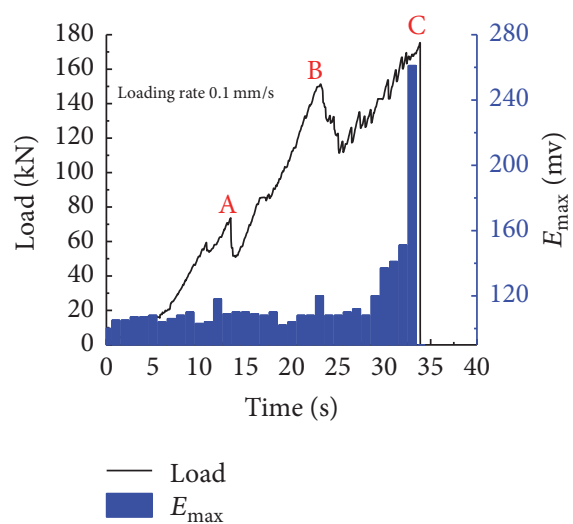

(a)
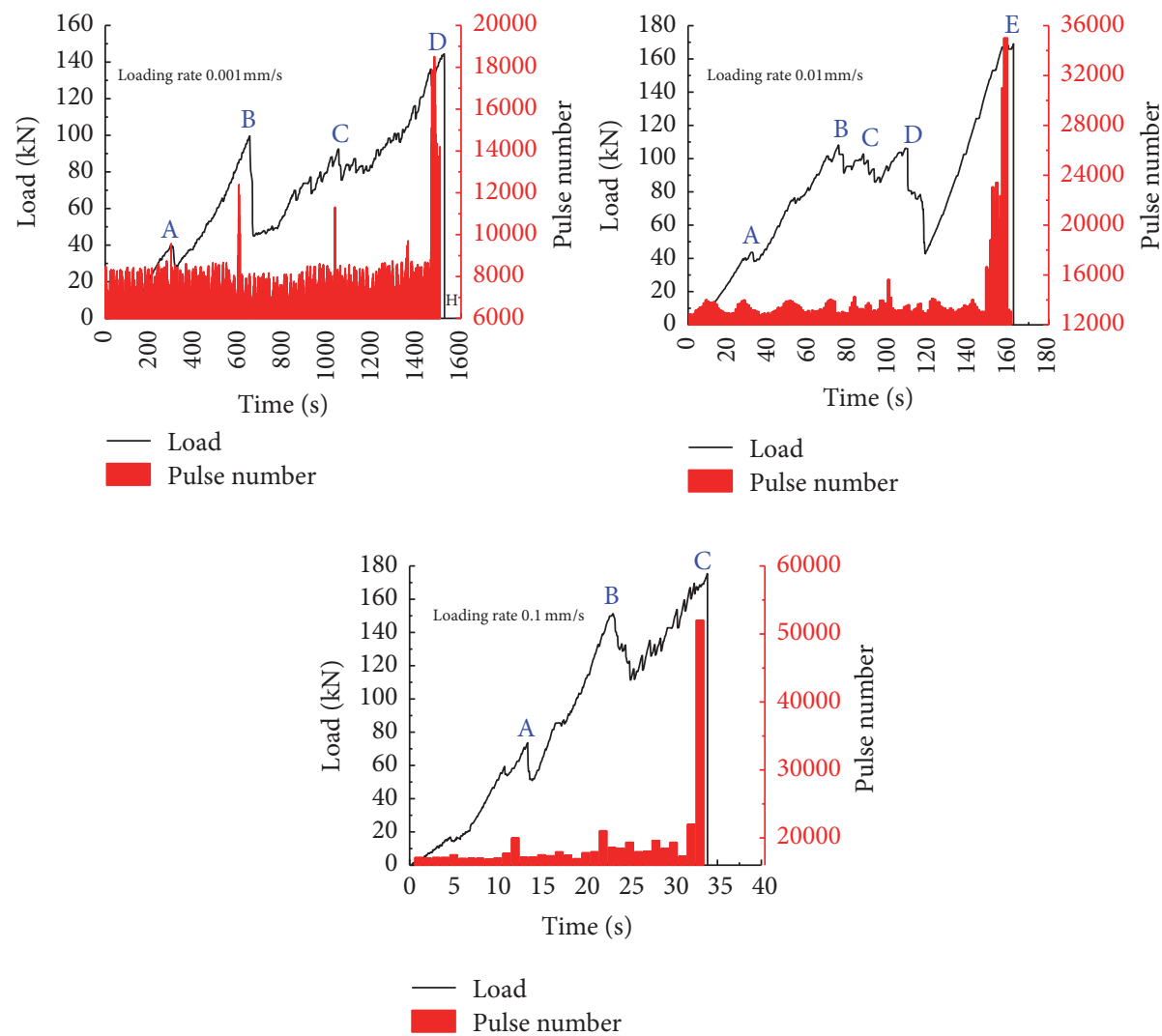

(b)

FIGURE 3: Curves of EME parameters under different loading rates. 

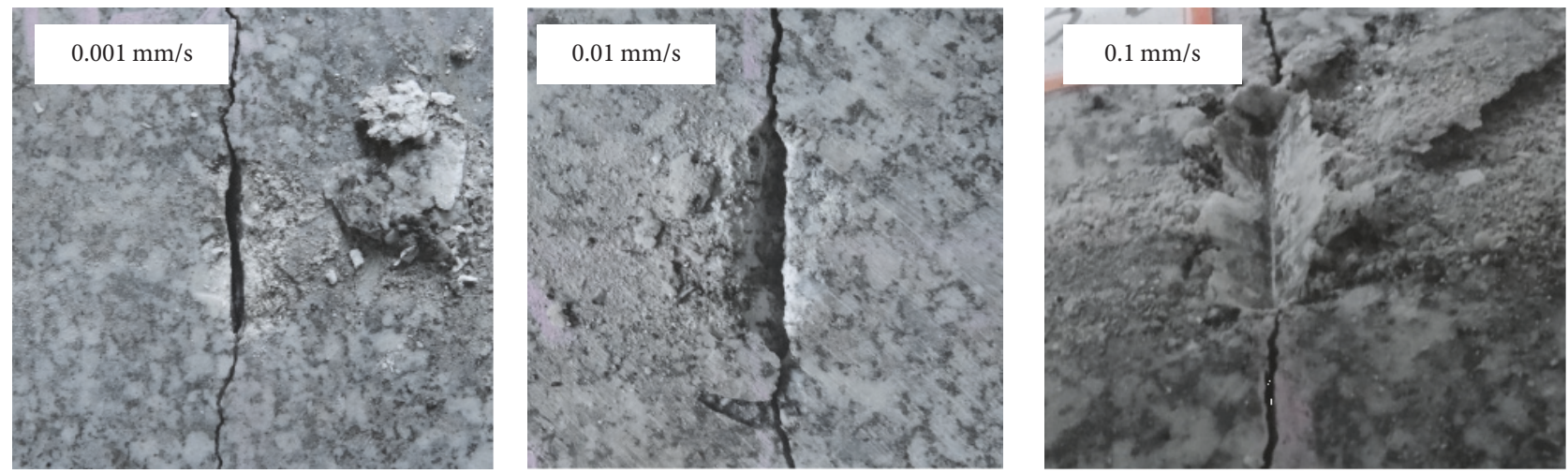

(a) Failure pattern of the granite at different loading rates
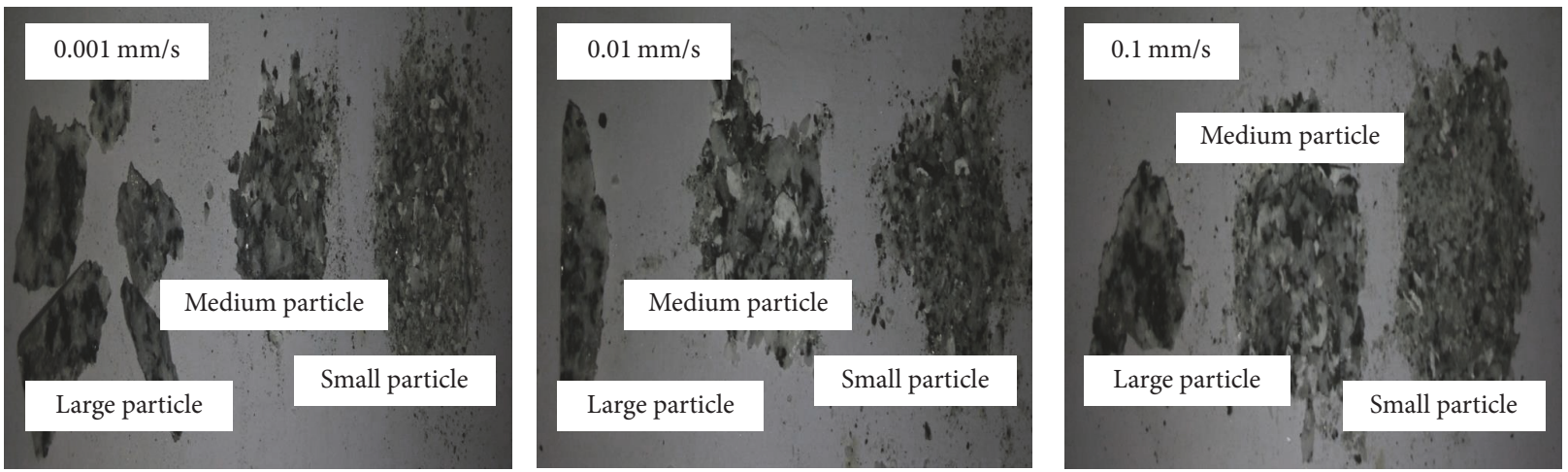

(b) The granite fragmentation at different loading rates

FIGURE 4: Failure characteristics of the granite at different loading rates.

According to Table 1, it can be seen that, in the ultimate load condition, the crush of granite increases with the loading rate. Besides, the peak value and the energy rate of the $\mathrm{AE}$ and the peak intensity and the number of pulses of the EME increasing gradually with the loading rate show good agreement with theoretical analysis.

(3) The EME signal generated by the granite failure with small loading rate shows large vibration before the EME signal reaches the first peak value. This can be interpreted as follows. The energy need to be accumulated when the cutter penetrates into the rock with the small loading rate, and the energy accumulation process affects the intensity of electromagnetic emission, resulting in the large vibration of the EME signal [31].

(4) As shown in Table 1, when the indentation load is near 95\% of the limit load, the AE and EME signals show jumping characteristics, reaching its maximum value. It means that the $\mathrm{AE}$ and the EME signal have a threshold. Since the thresholds of the AE and EME are reached before the rock broke, it is possible to use those thresholds to predict the rock damage instability.

4.2. Failure Characteristics of This Granite. The failure characteristics of this granite in the process of cutter invasion are given in Figure 4. Figure 4(a) shows this granite failure at different loading rates. When the cutter intrudes into the granite specimen, there is no obvious crack on the surface of the specimen. However, when the load reaches $95 \%$ of the limit load, the instantaneous failure of the specimen occurs suddenly and the expansion is rapid and violent. It can be found that the failure of the rock specimen is moving along one or a few main cracks, showing brittle fracture.

Compared with the failure mode of granite specimen under different loading rates, it can be found that the granite failure at different loading rates is similar to the one-word failure. The larger the loading rate is, the more severe the crack is, and the "crackling" sound can be heard simultaneously. Comparing the results in Figures 2 and 3 with the failure characteristics in Figure 4, one can find that the peak value and the energy rate of the $\mathrm{AE}$, and the peak intensity and the number of pulses of the EME are related to the size of the crack.

Figure 4(b) shows this granite fragmentation at different loading rates. When the sample is loaded with the rate of $0.001 \mathrm{~mm} / \mathrm{s}$, large particle fragmentation is the main fragmentation. In contrast, when the sample is loaded with the rate of $0.1 \mathrm{~mm} / \mathrm{s}$, small particle fragmentation is the main fragmentation. The loading rate has a great influence on rock failure pattern, as well as the rock fragmentation.

\section{Conclusions}

(1) This paper proposed the relationship among the generation of AE, EME, and the fracture stress of rock grain during 
rock broken process. Based on the relationships, the influence of loading rate on the characteristics of $\mathrm{AE}$ and EME of rock fragmentation is discussed. Theoretically, the AE and EME signals are enhanced with the increase of loading rate.

(2) Experimental results with three rates show that the loading rate has a significant effect on the AE and EME signals. The greater the loading rate is, the greater the intensity of the AE and EME signals produced is. The peak value and the energy rate of the $\mathrm{AE}$ and the peak intensity and the number of pulses of the EME increasing gradually with the loading rate show good agreement with theoretical analysis. Therefore, it is possible to use AE and EME technology to monitor the rock breaking process.

(3) Experimental results show that the AE and the EME signal have a threshold. Since the thresholds of the AE and EME are reached before the rock broke, it is possible to use those thresholds to predict the rock damage instability.

\section{Conflicts of Interest}

The authors declare that they have no conflicts of interest.

\section{Acknowledgments}

The support provided by the National Natural Science Foundation of China (Grants nos. 51474103 and 51674116) is gratefully acknowledged.

\section{References}

[1] D. Lockner, "The role of acoustic emission in the study of rock fracture," International Journal of Rock Mechanics and Mining Sciences, vol. 30, no. 7, pp. 883-899, 1993.

[2] E. Y. Wang, X. Q. He, Z. H. Chen et al., Coal and Rock Electromagnetic Radiation Technology and Its Application, Science Press, Beijing, China, 2009.

[3] L. G. Tham, H. Liu, C. A. Tang, P. K. K. Lee, and Y. Tsui, "On tension failure of 2-D rock specimens and associated acoustic emission," Rock Mechanics and Rock Engineering, vol. 38, no. 1, pp. 1-19, 2005.

[4] P. Ganne, A. Vervoort, and M. Wevess, "Quantification of prebreak brittle damage correlation between acoustic emission and observed micro-fracture," International Journal of Mechanics \& Mining Sciences, vol. 44, no. 5, pp. 720-729, 2007.

[5] Q. Huang, "One possible generation mechanism of co-seismic electric signals," Proceedings of the Japan Academy Series B: Physical and Biological Sciences, vol. 78, no. 7, pp. 173-178, 2002.

[6] V. Frid, "Calculation of electromagnetic radiation criterion for rockburts hazard forecast in coal mines," Pure and Applied Geophysics, vol. 158, no. 5-6, pp. 931-944, 2001.

[7] V. Frid and K. Vozoff, "Electromagnetic radiation induced by mining rock failure," International Journal of Coal Geology, vol. 64, no. 1-2, pp. 57-65, 2005.

[8] Z. G. Wang, M. Wang, G. Q. Zhang et al., "Spatial evolution rule of acoustic emission and fractal features of fractures in curtain body under uniaxial compression," Mining and Metallurgical Engineering, vol. 37, no. 1, pp. 5-9, 2017.

[9] X. B. Li, G. X. Wan, and Z. L. Zhou, "The relation between the frequency of electromagnetic radiation (EMR) induced by rock fracture and attribute parameters of rock masses," Chinese Journal of Geophysics, vol. 52, no. 1, pp. 253-259, 2009.

[10] Z. X. Wu, J. W. Liu, and J. P. Li, "Experimental study on time-frequency characteristics of AE generated during leptynite failure process," Mining and Metallurgical Engineering, vol. 33, no. 4, pp. 1-4, 10, 2013.

[11] H. Li, C. Yang, B. Li, and X. Yin, "Damage evolution and characteristics of ultrasonic velocity and acoustic emission for salt rock under triaxial multilevel loading test," Yanshilixue Yu Gongcheng Xuebao/Chinese Journal of Rock Mechanics and Engineering, vol. 35, no. 4, pp. 682-691, 2016.

[12] F. Zhao, H. Wang, Y. Peng, and G. Wang, "Experimental research on acoustic emission energy and rock crushing effect under static-dynamic coupling loading," Yanshilixue Yu Gongcheng Xuebao/Chinese Journal of Rock Mechanics and Engineering, vol. 31, no. 7, pp. 1363-1368, 2012.

[13] L. Dong, J. Wesseloo, Y. Potvin, and X. Li, "Discrimination of mine seismic events and blasts using the fisher classifier, naive bayesian classifier and logistic regression," Rock Mechanics and Rock Engineering, vol. 49, no. 1, pp. 183-211, 2016.

[14] V. L. Shkuratnik, Y. L. Filimonov, and S. V. Kuchurin, "Regularities of acoustic emission in coal samples under triaxial compression," Journal of Mining Science, vol. 41, no. 1, pp. 44$52,2005$.

[15] Z. H. Li, Q. Lou, and E. Y. Wang, "Experimental study of acoustic-electric and thermal infrared characteristics of roof rock failure," Journal of China University of Mining Technology, vol. 45, no. 6, pp. 1098-1103, 2016.

[16] S. Yang and Q. Yang, "Geometrically nonlinear transient response of laminated plates with nonlinear elastic restraints," Shock and Vibration, vol. 2017, Article ID 2189420, 9 pages, 2017.

[17] J. S. Kim, K. S. Lee, W. J. Cho, H. Choi, and G. Cho, "A comparative evaluation of stress-strain and acoustic emission methods for quantitative damage assessments of brittle rock," Rock Mechanics and Rock Engineering, vol. 48, no. 2, pp. 495508, 2015.

[18] L. J. Dong, J. Wesseloo, Y. Potvin, and X. B. Li, "Discriminant models of blasts and seismic events in mine seismology," International Journal of Rock Mechanics and Mining Sciences, vol. 86, pp. 282-291, 2016.

[19] G. C. Bessette, "Modeling blast loading on buried reinforced concrete structures with Zapotec," Shock and Vibration, vol. 15, no. 2, pp. 137-146, 2008.

[20] E. L. Zhao, E. Y. Wang, and Z. T. Liu, "Numerical simulation of electromagnetic radiation from coal or rock in a state of uniaxial compression," Journal of China University of Mining Technology, vol. 39, no. 5, pp. 648-651, 2010.

[21] W. R. Liu, Z. Q. Yi, A. Y. Yuan et al., "Particle-discrete-elementmethod-based research on acoustic emission characteristics and energy evolution laws of surrounding rock in different lithologic roadway," Journal of Mining \& Safety Engineering, vol. 34, no. 2, pp. 363-370, 2017.

[22] X. Li, Q. Wu, M. Tao, L. Weng, L. Dong, and Y. Zou, "Dynamic brazilian splitting test of ring-shaped specimens with different hole diameters," Rock Mechanics and Rock Engineering, vol. 49, no. 10, pp. 4143-4151, 2016.

[23] L. Dong, D. Sun, X. Li, and K. Du, "Theoretical and experimental studies of localization methodology for AE and microseismic sources without pre-measured wave velocity in mines," IEEE Access, vol. 5, pp. 16818-16828, 2017.

[24] L. Dong, W. Zou, X. Li, W. Shu, and Z. Wang, "Collaborative localization method using analytical and iterative solutions for 
microseismic/acoustic emission sources in the rockmass structure for underground mining," Engineering Fracture Mechanics, vol. 5, pp. 16818-16828, 2018.

[25] Z. M. Yuan, Y. K. Ma, and Z. Y. He, Acoustic Emission Technology and Its Application, Machinery Industry Press, Beijing, China, 1985.

[26] Z. D. Li, Z. M. Liu, and Y. J. Zhao, "Study on attenuation of ultrasonic waves in rocks," Journal of China Coal Society, vol. 22, no. 1, pp. 77-85, 1987.

[27] Z. H. Chen, Y. S. Can, and G. M. Yu, "Study on electromagnetic emission during rock failure," Journal of Liaoning Technical University Natural Science, vol. 17, no. 3, pp. 244-248, 1998.

[28] Z. Q. Guo, "A model of electromagnetic emissions from multicracking extension during rock fracture," Chinese Journal of Geophysics, vol. 42, no. S1, pp. 172-177, 1999.

[29] R. J. Wang, R. Q. Jiang, Han J. Z. et al., Hydraulic Percussion Rotary Drilling, Geological Publishing House, Beijing, China, 1988.

[30] O. Sano, I. Ito, and M. Terada, "Influence of strain rate on dilatancy and strength of Oshima granite under uniaxial compression," Journal of Geophysical Research: Solid Earth, vol. 86, no. B10, pp. 9299-9311, 1981.

[31] E. Y. Wang and E. L. Zhao, "Experiment study on electromagnetic emission character of rock and soil in process of uniaxial compression loading," Journal of Liaoning Technical University Natural Science, vol. 26, no. 1, pp. 56-58, 2007. 


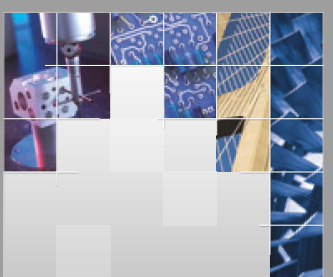

\section{Enfincering}
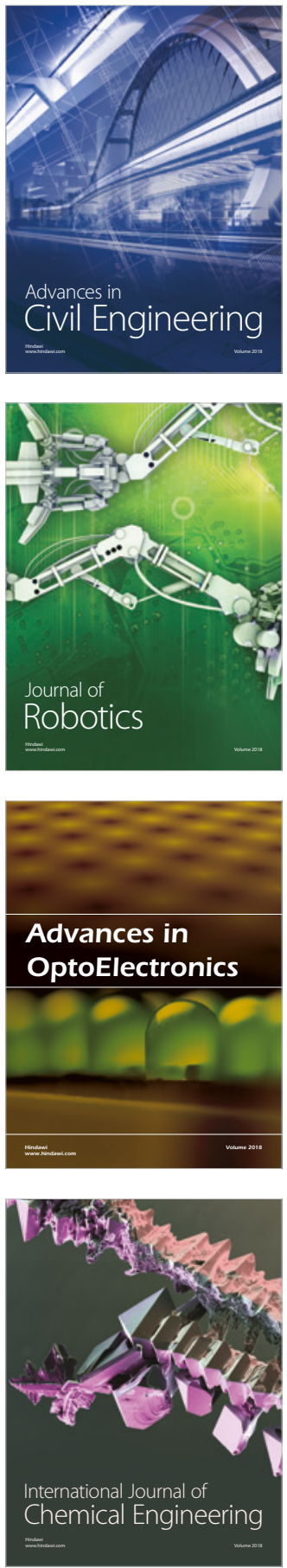

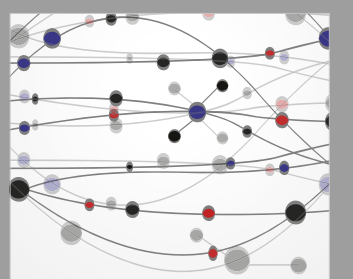

\section{Rotating \\ Machinery}

The Scientific World Journal

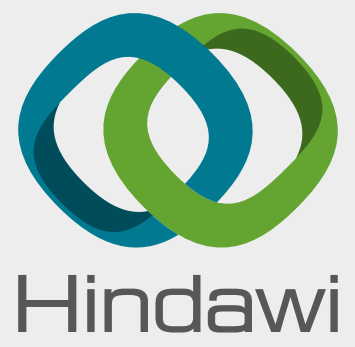

Submit your manuscripts at

www.hindawi.com
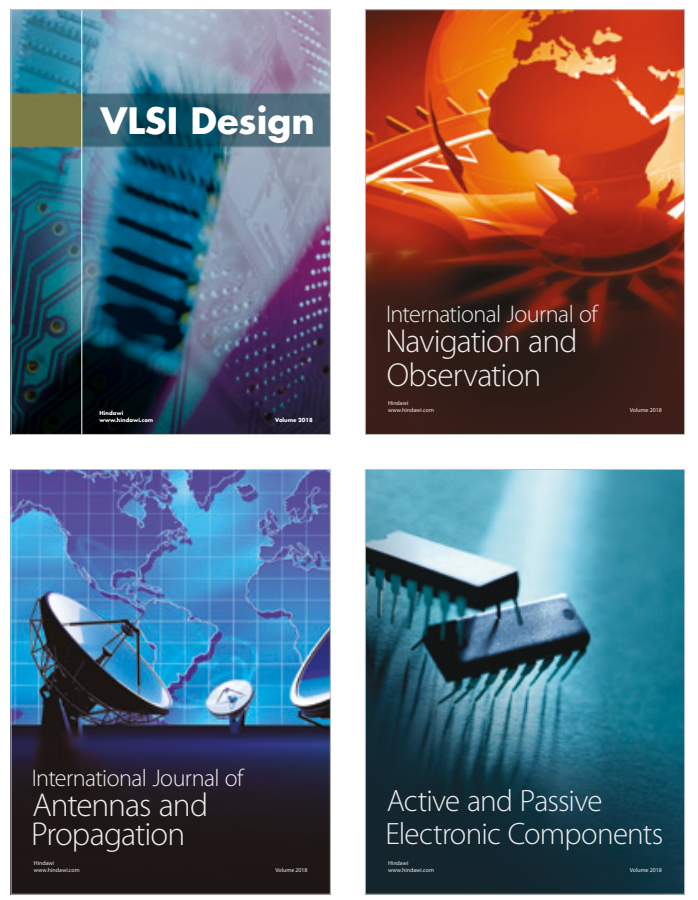
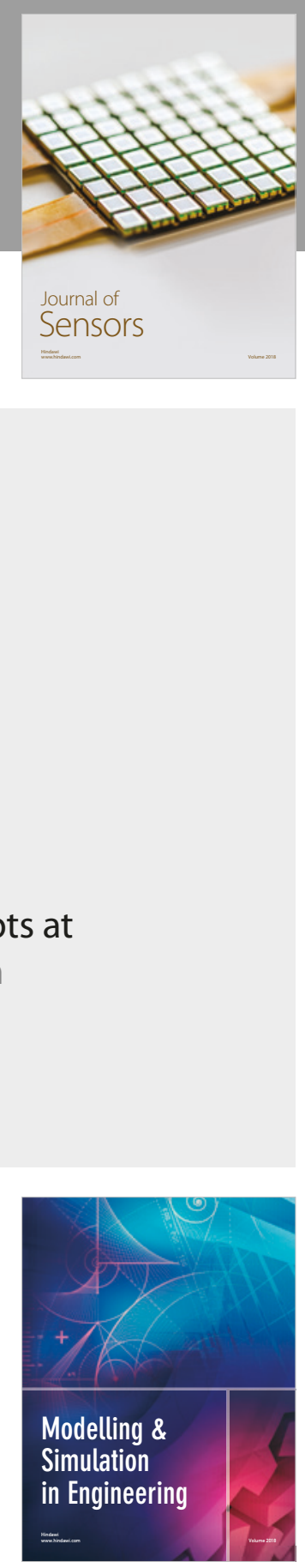

\section{Advances \\ Multimedia}
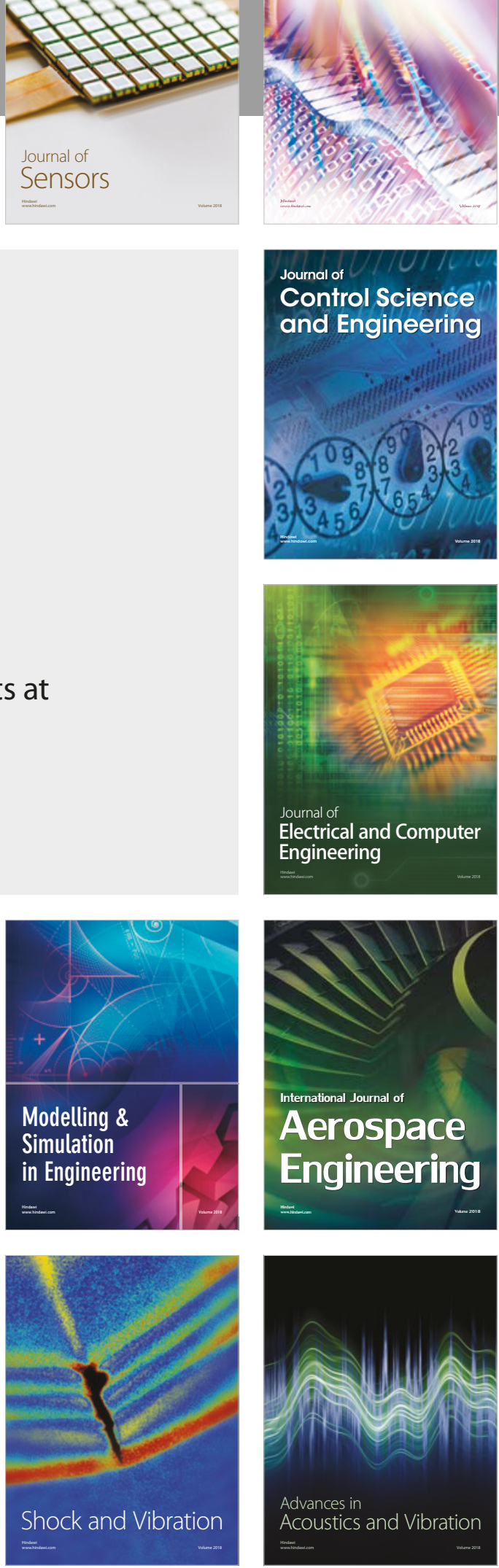